\title{
Duplex sonography for detection of deep vein thrombosis of upper extremities: a 13-year experience
}

\author{
Amy SY Chung *, WH Luk, Adrian XN Lo, CF Lo
}

\section{A B S T R A C T}

Objectives: To determine the prevalence and characteristics of sonographically evident upperextremity deep vein thrombosis in symptomatic Chinese patients and identify its associated risk factors.

Design: Case series.

Setting: Regional hospital, Hong Kong.

Patients: Data on patients undergoing upperextremity venous sonography examinations during a 13-year period from November 1999 to October 2012 were retrieved. Variables including age, sex, history of smoking, history of lower-extremity deep vein thrombosis, major surgery within 30 days, immobilisation within 30 days, cancer (history of malignancy), associated central venous or indwelling catheter, hypertension, diabetes mellitus, sepsis within 30 days, and stroke within 30 days were tested using binary logistic regression to understand the risk factors for upper-extremity deep vein thrombosis.

Main outcome measures: The presence of upperextremity deep vein thrombosis identified.

Results: Overall, 213 patients with upper-extremity sonography were identified. Of these patients, 29 (13.6\%) had upper-extremity deep vein thrombosis. The proportion of upper-extremity deep vein thrombosis using initial ultrasound was $0.26 \%$ of all deep vein thrombosis ultrasound requests. Upper
(37.9\%), history of cancer (65.5\%), and hypertension $(27.6 \%)$ were the more prevalent conditions among patients in the upper-extremity deep vein thrombosis-positive group. No statistically significant predictor of upper-extremity deep vein thrombosis was noted if all variables were included. After backward stepwise logistic regression, the final model was left with only age $(\mathrm{P}=0.119)$, female gender $(\mathrm{P}=0.114)$, and history of malignancy $(\mathrm{P}=0.024)$ as independent variables. History of malignancy remained predictive of upper-extremity deep vein thrombosis

Conclusions: Upper-extremity deep vein thrombosis is uncommon among symptomatic Chinese population. The most common sign is swelling and the major risk factor for upper-extremity deep vein thrombosis identified in this study is malignancy.

\section{Hong Kong Med J 2015;21:107-13}

DOI: $10.12809 / \mathrm{hkmj} 144389$

${ }^{1}$ ASY Chung *, MSc, MHKCRRT

2 WH Luk, FRCR, FHKAM (Radiology)

${ }^{3}$ AXN Lo, FRCR, FHKAM (Radiology)

${ }^{1}$ CF LO, PDDR

${ }^{1}$ Department of Radiology, United Christian Hospital, Kwun Tong, Hong Kong

Department of Radiology, Princess Margaret Hospital, Laichikok, Hong Kong

Department of Radiology, Hong Kong Adventist Hospital, 40 Stubbs Road, Hong Kong

* Corresponding author: chungsya@gmail.com

New knowledge added by this study

- Data suggest that upper-extremity deep vein thrombosis among ethnic Chinese is different from western population.

Implications for clinical practice or policy

- Patients with a history of malignancy should be given priority for ultrasound screening of upper-extremity deep vein thrombosis.

\section{Introduction}

It has been a long-held notion that in United Christian Hospital in Hong Kong, requests for upper-extremity vein sonography to screen for deep vein thrombosis (DVT) were rare. This may have been because upper-extremity deep vein thrombosis (UEDVT) was considered a benign phenomenon and not an urgent condition. However, UEDVT potentially carries certain risks like pulmonary embolism (PE), and leads to morbidity and mortality. Therefore, understanding the associated risk factors would help in improving the ability to predict and prevent the risk of PE.

In the past decade, most of the research 


\section{雙功能超聲檢測上肢深靜脈血栓：十三年 經驗分享}

鍾倩兒、陸永恆、羅煦寧、盧植暉

目的：找出具症狀的上肢深靜脈血栓華籍患者的患病率和超聲像特 徵, 以及確定其相關的危險因素。

設計：病例系列。

安排：香港一所分區醫院。

患者：分析了從1999年11月至2012年10月的13年間曾接受上肢靜脈 超聲檢查的病人數據紀錄。使用二元邏輯迴歸分析以下各項是否上肢 深靜脈血栓的危險因素：年齡、性別、吸煙史、下肢深靜脈血栓病 史、癌症（惡性腫瘤病史）、相關的中央靜脈或留置導管、高血壓、 糖尿病, 以及曾於 30 天內患有敗血症和中風。

主要結果測量：上肢深靜脈血栓的出現。

結果 : 研究期間曾接受上肢靜脈超聲檢查的共有 213 名患者。其中29 人 $(13.6 \%)$ 確診為上肢深靜脈血栓。在所有要求超聲檢查的深靜脈 血栓病例中, 最初使用超聲上肢深靜脈血栓的佔 $0.26 \%$ 。患者病發時 最常見的是上肢腫脹（206例；96.7\%）。確診為上肢深靜脈血栓的 患者中, 最多是有吸煙史 $(37.9 \%)$ 、癌症病史 $(65.5 \%)$ 和患有高 血壓 $(27.6 \%)$ 。如果把所有變量納入分析內, 會發現並無明顯的上 肢深靜脈血栓預測因素。向後逐步邏輯迴歸分析發現最終只有年齡

$(\mathrm{P}=0.119)$ 、女性 $(\mathrm{P}=0.114)$ 和惡性腫瘤病史 $(\mathrm{P}=0.024)$ 為獨立 變項。惡性腫瘤的病史仍然是上肢深靜脈血栓的預測因素。

結論：具症狀的華籍患者中上肢深靜脈血栓並不常見。最常見的症狀 為上肢腫脹, 而惡性腫瘤病史則為上肢深靜脈血栓的危險因素。

focused on identification and management of lowerextremity deep vein thrombosis (LEDVT), because UEDVT was believed to be clinically insignificant and quite rare, representing less than $2 \%$ of DVT. A study by Baarslag et $\mathrm{al}^{2}$ in 2004, however, reported that around half of their patients with UEDVT died during the follow-up period. More recent studies have challenged this belief. ${ }^{3-5}$ In 2004, Chan et al $^{6}$ reported a study comparing Chinese and Caucasian patients, and showed prevalence of LEDVT was different between the two populations $(9.1 \%$ proximal LEDVT without prophylaxis for Chinese and $16 \%$ proximal LEDVT with prophylaxis for Caucasians). This suggested that a study to assess the prevalence of UEDVT in Chinese population needs to be undertaken.

There are many imaging strategies to aid diagnosis of UEDVT. When comparing the different strategies, contrast venograms and computed tomography $(\mathrm{CT})$ venograms require the injection of contrast agents and involve radiation. With magnetic resonance venogram, however, no radiation is involved and can be performed without contrast injection. Unfortunately, the use of magnetic resonance venogram is limited by its high cost and inconvenience associated with the procedure.
On the other hand, colour duplex sonography is relatively cheap and more easily available. Colour duplex sonography provides excellent sensitivity and specificity as shown in a study by Köksoy et $\mathrm{al}^{7}$ in which the sensitivity and specificity were $94 \%$ and $96 \%$, respectively. According to these authors, the downside is that this technique cannot completely exclude the presence of thrombus in axillary, subclavian, superior vena cava, or brachiocephalic vessels. ${ }^{7}$ The presence of UEDVT may onlybe inferred from secondary signs such as absence of respiratory variation and cardiac plasticity. ${ }^{8}$ In view of its safety and cost-effectiveness, duplex sonography is usually preferred as the first-line imaging technique in the evaluation of UEDVT.

The aims of this study were to determine the prevalence and characteristics of sonographically evident UEDVT in symptomatic Chinese patients and identify the associated risk factors.

\section{Methods}

\section{Methodology}

A retrospective study was conducted in a regional hospital in a district where the socio-economic status was similar to the rest of the population in Hong Kong. ${ }^{9}$ The study sample was comprised of patients undergoing an initial duplex sonography of the upper extremity for suspicion of UEDVT during the period November 1999 to October 2012. The study began with an initial search on the computerised Radiology Information System of the Hong Kong Hospital Authority and patients undergoing duplex sonography of upper- or lower-extremity veins were identified. From the radiology reports, positive cases of DVT (both UEDVT and LEDVT) were sourced using key words "incomplete compressibility", "noncompressible", "incompressible", "not compressible", or "compressibility: (no)". The search was further narrowed down to retrieve patients with radiology reports and images of all upper-extremity vein sonography using key words in reports like "upper extremity vein" or "upper limb vein".

Since the demographic profile of Hong Kong is mainly ethnic Chinese, our study included only Chinese patients who underwent initial upperextremity sonography for the detection of UEDVT within the defined period. Studies that were incomplete for any reason and patients who had a positive finding of UEDVT from a previous scan were excluded. Medical record search was performed for the selected patients through the electronic Patient Record System.

\section{Data collection and analysis}

The medical records were reviewed and data on patient demographic characteristics, possible risk factors, and co-morbidities were collected. All 
confidential patient data were de-identified and each patient was assigned a study number before analysis. Standardised data collection charts were used to gather information, and details of information recorded are shown in Table 1.

The radiology reports and images were reviewed by two experienced, qualified radiologists, with each radiologist having more than 10 years of experience. The diagnosis of UEDVT was primarily based on the incomplete compressibility of the veins on sonography. ${ }^{3}$ When Doppler evaluation was used, absence of flow, lack of respiratory variation, or cardiac plasticity were used as secondary criteria for diagnosis. ${ }^{3}$ Central lines were considered to be present if mentioned in the sonography report, in the medical record, or documented on chest radiography, venography, CT or other imaging modality within 4 weeks prior to sonography. The catheter size and catheter material were not considered or correlated, as such information was not readily available retrospectively. Patients who presented with a history of vigorous exercise within 4 weeks of UEDVT were classified as effort-related. ${ }^{10}$ In contrary, when no forceful activity of limb or predisposing factor was observed before onset of symptoms, UEDVT was classified as idiopathic or spontaneous. ${ }^{9}$ Any discrepancies in the report or findings were addressed according to a consensus by the two reviewing radiologists.

Preliminary data analysis was performed using descriptive statistics. The mean values of patient's age and frequency distribution among both genders were calculated in the UEDVT-negative and UEDVT-positive groups. $t$ Test was used to examine the differences in age between the two groups and $\mathrm{P}<0.05$ was regarded as significant. The frequency distributions of signs and symptoms including swelling, extremity discomfort, erythema, dyspnoea, chest pain, and cough were compared in the two groups. The frequency proportions of the variables in the two groups were calculated. Variables including age, sex, history of smoking and LEDVT, major surgery within 30 days, immobilisation within 30 days, cancer (history of malignancy), associated CVC (central venous or indwelling catheter), hypertension, diabetes mellitus, sepsis within 30 days, and stroke within 30 days were tested using binary logistic regression. Using backward stepwise logistic regression, the variables with the highest $P$ values were eliminated one by one until all the remaining variables had $\mathrm{P} \leq 0.2$, and $\mathrm{P}<0.05$ was considered significant. The most prevalent risk factor in the UEDVT-positive group was identified and compared with data from Caucasian population. All statistical comparisons were done using the Statistical Package for the Social Sciences (Windows version 19.0; SPSS Inc, Chicago [IL], US).
TABLE I. Summary of data recorded in data collection chart

\begin{tabular}{|c|c|}
\hline \multirow[t]{3}{*}{ Demographic data } & Age \\
\hline & Sex \\
\hline & Smoker \\
\hline \multirow[t]{10}{*}{ Signs and symptoms } & None \\
\hline & Swelling \\
\hline & Extremity discomfort \\
\hline & Erythema \\
\hline & Dyspnoea \\
\hline & Chest pain \\
\hline & Cough \\
\hline & Syncope \\
\hline & Confirmed PE \\
\hline & Others \\
\hline \multirow[t]{14}{*}{ Risk factors } & History of PE \\
\hline & History of LEDVT \\
\hline & Family history of VTE \\
\hline & Major surgery within 30 days \\
\hline & Immobilisation within 30 days \\
\hline & General anaesthesia \\
\hline & Cancer patient (type) \\
\hline & - Active cancer with ongoing radiation therapy \\
\hline & - Active cancer with ongoing chemotherapy \\
\hline & Catheter associated (region) \\
\hline & Major trauma \\
\hline & Hormone replacement therapy \\
\hline & Pregnant or postpartum \\
\hline & Hormonal contraceptives \\
\hline \multirow[t]{12}{*}{ Co-morbidities } & Hypertension \\
\hline & Diabetes mellitus \\
\hline & Neurological disease \\
\hline & Non-pulmonary infection \\
\hline & Congestive heart failure \\
\hline & Chronic obstructive pulmonary disease \\
\hline & Dialysis dependent \\
\hline & Sepsis $<30$ days \\
\hline & Bronchitis or pneumonia $<30$ days \\
\hline & Organ transplant \\
\hline & Gastro-intestinal bleed requiring transfusion $<30$ days \\
\hline & Stroke $<30$ days \\
\hline \multirow{3}{*}{$\begin{array}{l}\text { Prophylactic measures } \\
\text { within } 30 \text { days }\end{array}$} & Pharmacological prophylaxis \\
\hline & Warfarin \\
\hline & Low-molecular-weight heparin \\
\hline
\end{tabular}

Abbreviations: LEDVT = lower-extremity deep vein thrombosis; PE = pulmonary embolism; VTE = venous thromboembolism 


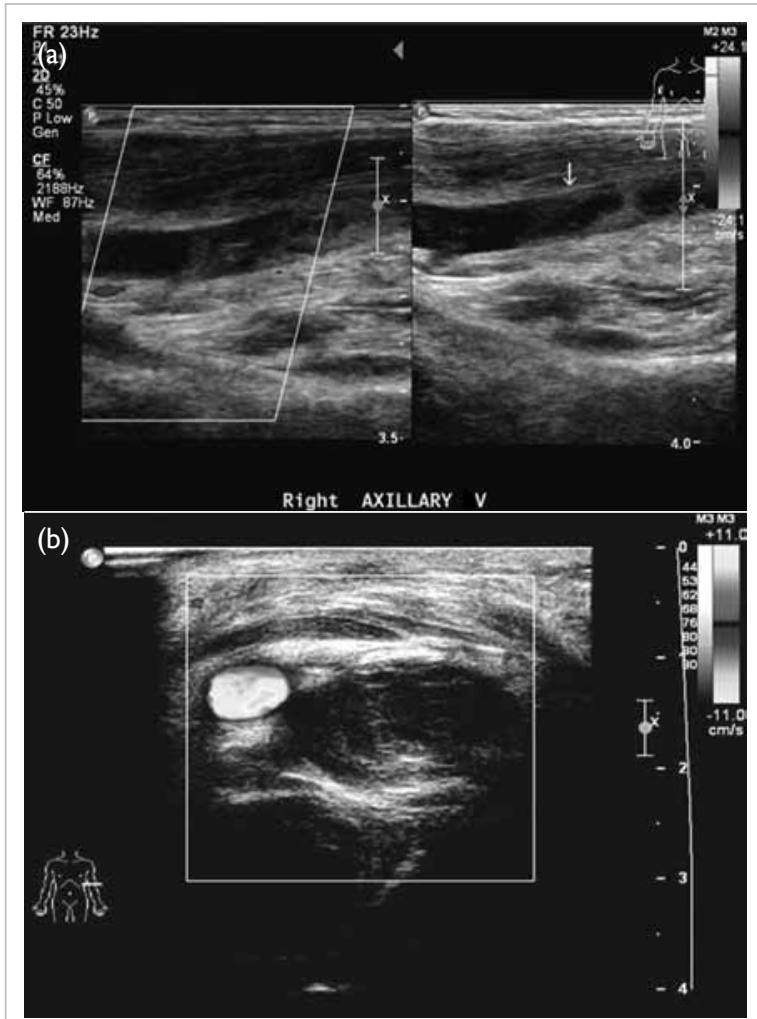

FIG. Ultrasound images of (a) a patient diagnosed with breast carcinoma: it shows lack of colour signals inside the vein (thrombus formation); and (b) a patient with colon carcinoma in bed-bound palliative care: it shows large thrombus inside the vein lumen

\section{Results}

Between November 1999 and October 2012, 11019 patients had undergone upper- or lower-extremity vein ultrasound examinations in the hospital. Major proportion of requests (10 783 patients, $97.9 \%$ ) was for lower-extremity vein ultrasound. Ultrasound diagnosis of DVT (UEDVT and LEDVT) was seen in $822(7.6 \%)$ patients, of which UEDVT was seen in 34 (4.1\%) patients and LEDVT in 788 (95.9\%) patients during that period.
Overall there were 236 upper-extremity vein ultrasound requests, of which 23 patients (5 out of 23 patients had UEDVT) were excluded as they did not meet the inclusion criteria (an initial upperextremity vein sonography). A total of 213 patients were included in the study sample; UEDVT was diagnosed in $29(13.6 \%)$ of the study sample (Fig). Therefore, the proportion of UEDVT diagnosed by initial ultrasound was only $0.26 \%(29 / 11019)$ of all DVT (upper and lower extremity) ultrasound requests. The demographic characteristics of patients in the UEDVT-negative and UEDVTpositive groups are shown in Table 2 .

When comparing the age distribution between the two groups with $t$ test, the results were not significant $(\mathrm{P}=0.06)$. In the UEDVT-negative group, 74 (40.2\%) patients were males and $110(59.8 \%)$ patients were females. There was no significant difference in age distribution among the two genders $(\mathrm{P}=0.394)$. Among the UEDVT-positive group, 15 (51.7\%) patients were males and $14(48.3 \%)$ were females. $t$ Test to compare the age distribution between the two genders in this group was also not significantly different $(\mathrm{P}=0.257)$.

The frequency distributions of the signs and symptoms in the two groups are summarised in Table 3. Most patients in the UEDVT-negative group presented with upper limb swelling, and was seen in 178 (96.7\%) patients. Even among the UEDVTpositive group patients, upper limb swelling was the most common sign, and was present in 28 (96.6\%) patients.

Statistical analysis and frequency proportion of variables in the two groups are summarised in Table 4. In the UEDVT-negative group, history of cancer, hypertension, and diabetes mellitus appeared to be the more prevalent variables and was seen in 82 (44.6\%), 81 (44.0\%) and 47 (25.5\%), respectively. On the other hand, among the 29 patients in the UEDVT-positive group, history of smoking, history of cancer, and hypertension were the prevalent risk factors, and was seen in 11 (37.9\%), 19 (65.5\%) and 8 (27.6\%) patients, respectively.

Binary logistic regression was used to test

TABLE 2. Age and sex distribution of patients*

\begin{tabular}{|c|c|c|c|c|}
\hline & \multicolumn{2}{|c|}{ UEDVT-negative group $(n=184)$} & \multicolumn{2}{|c|}{ UEDVT-positive group $(\mathrm{n}=29)$} \\
\hline & Male & Female & Male & Female \\
\hline No. of patients & $74(40.2 \%)$ & $110(59.8 \%)$ & $15(51.7 \%)$ & $14(48.3 \%)$ \\
\hline Overall mean age (years) & \multicolumn{2}{|c|}{$71.6 \pm 15.7$} & \multicolumn{2}{|c|}{$66.7 \pm 15.5$} \\
\hline Overall age range (years) & \multicolumn{2}{|c|}{$28-100$} & \multicolumn{2}{|c|}{$32-95$} \\
\hline Mean age (years) & $72 \pm 14.1$ & $71.3 \pm 16.7$ & $64.9 \pm 17.1$ & $68.7 \pm 13.9$ \\
\hline Age range (years) & $28-93$ & $30-100$ & $32-92$ & $50-95$ \\
\hline
\end{tabular}

Abbreviation: UEDVT = upper-extremity deep vein thrombosis

* Data are shown as No. (\%), range, or mean \pm standard deviation 
the variables (Table 4). There were no statistically significant predictors of UEDVT if all variables were included. There was a trend towards higher risk of UEDVT in patients with a history of malignancy (odds ratio $[\mathrm{OR}]=2.250, \quad \mathrm{P}=0.071$ ) but this was not statistically significant. Stepwise backward regression was performed to eliminate the independent variables with the highest $P$ value until $P \leq 0.2$. The final regression model was left with only age, sex, and history of malignancy as independent variables, as the other variables persistently showed high P values (Table 5).

In this study, the remaining variables in the model were age $(\mathrm{P}=0.119)$, female gender $(\mathrm{P}=0.114)$, and history of malignancy $(\mathrm{P}=0.024)$. History of malignancy remained predictive of UEDVT, and positive history of malignancy had an OR of 2.664 (95\% confidence interval, 1.140-6.211) for the presence of UEDVT.

In the UEDVT-positive group, there was no obvious predisposing cause observed in three patients. Therefore, these three (10.3\%) patients were classified as having primary UEDVT, while the remaining $26(89.7 \%)$ patients were classified as secondary UEDVT.

\section{Discussion}

In our study, the number of UEDVT cases diagnosed during the 13-year period using initial sonography was about 2.2 patients per year. As stated earlier, it has been a long-held perspective that UEDVT screening was a rare request in our hospital, and this is clearly evident from this study. Requests for UEDVT sonography constituted only $2.1 \%$ (236/11 019) of all extremity (upper and lower) vein ultrasound requests. The proportion of UEDVT diagnosed by initial ultrasound was only $0.26 \%$ of all DVT (upper and lower extremity) ultrasound requests, and therefore very rare.

Among 29 patients with UEDVT in our study, three patients presented with no obvious predisposing cause. One young healthy 32-year-old male claimed to have developed symptoms after exercise, and so this particular case was classified as primary effort-related thrombosis. Effort-related UEDVT often affected individuals who were young and healthy, with a male-to-female ratio of approximately $2: 1 .^{11}$ The incidence is higher in males and similar findings were also found in this study, and males were younger than females. Pain and swelling are commonly present in patients with UEDVT as shown in a study by Mustafa et al. ${ }^{4}$ Similarly, swelling was the most prevalent sign in our study, which was seen in $96.6 \%$ of patients, and represented the most common sign of UEDVT.

In our study, the prevalence of UEDVT among those undergoing ultrasound examinations for suspected UEDVT was $13.6 \%$, and is the lowest when
TABLE 3. Frequency distribution of signs and symptoms in both UEDVT-negative and -positive groups

\begin{tabular}{lcc}
\hline & $\begin{array}{c}\text { UEDVT-negative group } \\
(\mathbf{n = 1 8 4 )}\end{array}$ & $\begin{array}{c}\text { UEDVT-positive group } \\
(\mathbf{n = 2 9 )}\end{array}$ \\
\hline Upper limb swelling & $178(96.7 \%)$ & $28(96.6 \%)$ \\
Extremity discomfort & $138(75.0 \%)$ & $26(89.7 \%)$ \\
Erythema & $25(13.6 \%)$ & $4(13.8 \%)$ \\
Dyspnoea & $10(5.4 \%)$ & $3(10.3 \%)$ \\
Chest pain & $3(1.6 \%)$ & $1(3.4 \%)$ \\
Cough & $7(3.8 \%)$ & $1(3.4 \%)$ \\
\hline
\end{tabular}

Abbreviation: UEDVT = upper-extremity deep vein thrombosis

TABLE 4. Statistical analysis and frequency proportion of variables in the UEDVTnegative and -positive groups

\begin{tabular}{lcccc}
\hline Variable & $\begin{array}{c}\text { UEDVT-negative } \\
\text { group (n=184) }\end{array}$ & $\begin{array}{c}\text { UEDVT-positive } \\
\text { group }(\mathbf{n}=\mathbf{2 9})\end{array}$ & P value & $\begin{array}{c}\text { Odds } \\
\text { ratio }\end{array}$ \\
\hline Age (years) & - & - & 0.375 & 0.987 \\
\hline Sex (female) & $110(59.8 \%)$ & $14(48.3 \%)$ & 0.294 & 0.584 \\
\hline History of smoking & $43(23.4 \%)$ & $11(37.9 \%)$ & 0.516 & 1.410 \\
\hline History of LEDVT & $14(7.6 \%)$ & $2(6.9 \%)$ & 0.998 & 0.998 \\
\hline Major surgery $<30$ days & $3(1.6 \%)$ & $1(3.4 \%)$ & 0.853 & 1.284 \\
\hline Immobilisation $<30$ days & $44(23.9 \%)$ & $5(17.2 \%)$ & 0.871 & 0.903 \\
\hline History of cancer & $82(44.6 \%)$ & $19(65.5 \%)$ & 0.071 & 2.250 \\
\hline Associated CVC & $19(10.3 \%)$ & $3(10.3 \%)$ & 0.867 & 1.123 \\
\hline Hypertension & $81(44.0 \%)$ & $8(27.6 \%)$ & 0.603 & 0.751 \\
\hline Diabetes mellitus & $47(25.5 \%)$ & $5(17.2 \%)$ & 0.761 & 0.837 \\
\hline Sepsis $<30$ days & $8(4.3 \%)$ & $1(3.4 \%)$ & 0.786 & 0.735 \\
\hline Stroke $<30$ days & $11(6.0 \%)$ & 0 & 0.999 & 0.000 \\
\hline
\end{tabular}

Abbreviations: CVC = central venous or indwelling catheter; LEDVT = lower-extremity deep vein thrombosis; UEDVT = upper-extremity deep vein thrombosis

TABLE 5. Analysis of risk factors for UEDVT (remaining variables after backward stepwise regression)

\begin{tabular}{lcc}
\hline Variable & Odds ratio (95\% confidence interval) & P value \\
\hline Age & $0.980(0.956-1.005)$ & 0.119 \\
Sex (female) & $0.516(0.228-1.171)$ & 0.114 \\
Cancer patients & $2.664(1.140-6.211)$ & 0.024 \\
\hline
\end{tabular}

Abbreviation: UEDVT = upper-extremity deep vein thrombosis

compared with other studies conducted among Caucasian population $\left(18 \%,{ }^{12} 40 \%,{ }^{13} 25 \%,{ }^{14}\right.$ and $\left.40 \%{ }^{5}\right)$. We also observed that there were fewer patients with indwelling catheters in our study sample compared with other studies $\left(10.3 \%\right.$ vs $11.6 \%,{ }^{13} 12 \%,{ }^{12} 23 \%,{ }^{14}$ and $57 \% 5)$. Earlier reports by Joffe et $\mathrm{al}^{3}$ suggested that indwelling catheter was the strongest predictor 
of UEDVT, and this may be the reason for the lower incidence in our study compared with other studies.

Overall, in our study it was found that history of smoking (37.9\%), malignancy (65.5\%), and hypertension (27.6\%) were the common risk factors and particularly in UEDVT group (Table 4). Statistical analysis showed that a history of malignancy remained predictive of UEDVT. In our study, malignancy was a major risk factor for UEDVT, similar to studies conducted in Caucasian population. ${ }^{1,3,4}$ In our study, the frequency of cancer (65.5\%) was even higher than those in Caucasian population in other studies, which had $43 \%,{ }^{15} 30 \%,{ }^{16}$ $38 \%,{ }^{17}$ and $45 \% .{ }^{4}$

Similar studies on Chinese population have already been published. Chen et $\mathrm{al}^{18}$ have investigated the differences in limb, age, and sex of Chinese patients with LEDVT. Abdullah et $\mathrm{al}^{19}$ studied the incidence of UEDVT associated with peripherally inserted central catheters. Liu et $\mathrm{al}^{20}$ estimated the incidence of venous thromboembolism instead of UEDVT in a study from a Hong Kong regional hospital. However, no study relating to prevalence of UEDVT comparing Chinese and western population have been performed. This study, while important, highlighted malignancy as the major risk factor for the prevalence of UEDVT. In a resourcelimited health care system, patients with a history of malignancy should be prioritised in the triage of symptomatic patients referred for UEDVT screening, because malignancy is a major predictor of UEDVT and carries risk of PE. Such prioritisation will be beneficial to UEDVT patients as they can be identified and treated early.

\section{Limitations}

We employed retrospective observation in this study, and data were collected only from those available in the medical records. Therefore, the frequency of UEDVT reported might grossly underestimate the true number. The reason for this could be that signs and symptoms of UEDVT are usually nonspecific, and as reported in other prospective studies many patients with UEDVT may remain completely asymptomatic. $^{21}$

In our study, diagnosis of UEDVT was made solely by ultrasound. Studies have shown that ultrasound imaging has excellent sensitivity and specificity for LEDVT. ${ }^{22,23}$ In a study, the sensitivity had reached $97 \%$ to $100 \%$ and specificity of $98 \%$ to 99\%. ${ }^{18}$ However, previous studies have reported lower sensitivity and specificity for upper-extremity ultrasound at $78 \%$ to $100 \%$ and $82 \%$ to $100 \%$, respectively. ${ }^{18,19}$ There are several possible reasons why the sensitivity and specificity for detecting UEDVT are lower compared with LEDVT. One main reason is because of the anatomic drawback. The sternum and clavicle create acoustic shadowing or artefact on ultrasound imaging which limits the visualisation of proximal upper-extremity veins and thereby explains the relatively low sensitivity and specificity. ${ }^{3}$ Additionally, it would be difficult to visualise the centrally situated veins like the medial segment of the subclavian vein, the brachiocephalic vein, and their confluence with the superior vena cava. ${ }^{24}$ Moreover, the presence of a catheter might not only alter the venous tone, but also affect the venous flow making it more difficult to interpret the Doppler findings visualised on ultrasound. Further, differentiation between a normal vein and a large collateral in a patient with chronic venous thrombosis might sometimes be difficult. ${ }^{20}$ Another limitation of our study was the relatively small sample size, especially for catheter-related patients. Such small numbers might preclude subgroup analysis and lower the statistical power for identifying risk factors.

\section{Conclusions}

The major risk factor for UEDVT identified from this study is malignancy. Therefore, patients with a history of malignancy should be prioritised in the triage of symptomatic patients referred for UEDVT screening because malignancy is a major predictor of UEDVT and carries risk for PE.

\section{References}

1. Tilney ML, Griffiths HJ, Edwards EA. Natural history of major venous thrombosis of the upper extremity. Arch Surg 1970;101:792-6.

2. Baarslag HJ, Koopman MM, Hutten BA, et al. Long-term follow-up of patients with suspected deep vein thrombosis of the upper extremity: survival, risk factors and postthrombotic syndrome. Eur J Intern Med 2004;15:503-7.

3. Joffe HV, Kucher N, Tapson VF, Goldhaber SZ; Deep Vein Thrombosis (DVT) FREE Steering Committee. Upperextremity deep vein thrombosis: a prospective registry of 592 patients. Circulation 2004;110:1605-11.

4. Mustafa S, Stein PD, Patel KC, Otten TR, Holmes R, Silbergleit A. Upper extremity deep venous thrombosis. Chest 2003;123:1953-6.

5. Giess CS, Thaler H, Bach AM, Hann LE. Clinical experience with upper extremity sonography in a high-risk cancer population. J Ultrasound Med 2002;21:1365-70.

6. Chan YK, Chiu KY, Cheng SW, Ho P. The incidence of deep vein thrombosis in elderly Chinese suffering hip fracture is low without prophylaxis: a prospective study using serial duplex ultrasound. J Orthop Surg (Hong Kong) 2004;12:178-83.

7. Köksoy C, Kuzu A, Kutlay J, Erden I, Ozcan H, Ergîn K. The diagnostic value of colour Doppler ultrasound in central venous catheter related thrombosis. Clin Radiol 1995;50:687-9.

8. Marshall PS, Cain H. Upper extremity deep vein thrombosis. Clin Chest Med 2010;31:783-97.

9. Statistical tables of the 2006 population by-census. Available from: http://www.bycensus2006.gov.hk/en/data/ data3/statistical_tables/index.htm\#A2. Accessed 9 Dec 
2014.

10. Joffe HV, Goldhaber SZ. Upper-extremity deep vein thrombosis. Circulation 2002;106:1874-80.

11. Illig KA, Doyle AJ. A comprehensive review of PagetSchroetter syndrome. J Vasc Surg 2010;51:1538-47.

12. Kerr TM, Lutter KS, Moeller DM, et al. Upper extremity venous thrombosis diagnosed by duplex scanning. Am J Surg 1990;160:202-6.

13. Kröger K, Schelo C, Gocke C, Rudofsky G. Colour Doppler sonographic diagnosis of upper limb venous thromboses. Clin Sci (Lond) 1998;94:657-61.

14. Lee JA, Zierler BK, Zierler RE. The risk factors and clinical outcomes of upper extremity deep vein thrombosis. Vasc Endovascular Surg 2012;46:139-44.

15. Marinella MA, Kathula SL, Markert RJ. Spectrum of upper-extremity deep venous thrombosis in a community teaching hospital. Heart Lung 2000;29:113-7.

16. Isma N, Svensson PJ, Gottsäter A, Lindblad B. Upper extremity deep venous thrombosis in the populationbased Malmö thrombophilia study (MATS). Epidemiology, risk factors, recurrence risk, and mortality. Thromb Res 2010;125:335-8.

17. Muñoz FJ, Mismetti P, Poggio R, et al. Clinical outcome of patients with upper-extremity deep vein thrombosis: results from the RIETE Registry. Chest 2008;133:143-8.
18. Chen F, Xiong JX, Zhou WM. Differences in limb, age and sex of Chinese deep vein thrombosis patients. Phlebology 2014 Feb 14. Epub ahead of print.

19. Abdullah BJ, Mohammad N, Sangkar JV, et al. Incidence of upper limb venous thrombosis associated with peripherally inserted central catheters (PICC). Br J Radiol 2005;78:596600.

20. Liu HS, Kho BC, Chan JC, et al. Venous thromboembolism in the Chinese population-experience in a regional hospital in Hong Kong. Hong Kong Med J 2002;8:400-5.

21. Luciani A, Clement O, Halimi P, et al. Catheter-related upper extremity deep venous thrombosis in cancer patients: a prospective study based on Doppler US. Radiology 2001;220:655-60.

22. Prandoni P, Polistena P, Bernardi E, et al. Upper-extremity deep vein thrombosis. Risk factors, diagnosis, and complications. Arch Intern Med 1997;157:57-62.

23. Baarslag HJ, van Beek EJ, Koopman MM, Reekers JA. Prospective study of color duplex ultrasonography compared with contrast venography in patients suspected of having deep venous thrombosis of the upper extremities. Ann Intern Med 2002;136:865-72.

24. Chin EE, Zimmerman PT, Grant EG. Sonographic evaluation of upper extremity deep venous thrombosis. J Ultrasound Med 2005;24:829-38; quiz 839-40. 